\title{
Behavioral Inhibition System (BIS), Behavioral Activation System (BAS), and grandiose facets of narcissism
}

\author{
Łukasz Subramanian $^{1} \cdot$ Michał Sękowski $^{1}$ - Magdalena Żemojtel-Piotrowska ${ }^{1}$ \\ Published online: 15 July 2020 \\ (C) The Author(s) 2020
}

\begin{abstract}
The current study examines the temperamental basis of three forms of grandiose narcissism (i.e., agentic, communal, and antagonistic), employing the Behavioral Inhibition System model and three aspects of Behavioral Activation System (i.e., drive, pleasureseeking, and sensitivity to reward). Using a self-report study conducted on a general Polish sample $(N=657)$, we found that all forms of narcissism were positively associated with all three aspects of BAS, while BIS was negatively associated with agentic and antagonistic forms. Communal and antagonistic narcissism did not differ in comparison of their correlations with drive and sensitivity to reward, while agentic narcissism indicated the strongest relations to temperament. A multiple regression indicated that each of the three forms of narcissism has its own specific relationship with BIS and of the aspects of BAS. We discuss our findings as useful in explaining how the three forms of narcissism are related to BIS and BAS with the distinction of the latter into its three aspects, indicating substantial differences between agentic and communal narcissism, and specificity of antagonistic narcissism.
\end{abstract}

Keywords Narcissism · Agentic narcissism · Antagonistic narcissism · Communal narcissism · Grandiose narcissism

\section{Introduction}

Narcissism is one of the most broadly studied phenomena in psychology.

(Krizan and Herlache 2018; Miller et al. 2017). Despite numerous controversies related to its definition and conceptualisation (see Miller et al. 2017 for review), there generally agreement about its heterogeneity (Back et al. 2013; Gebauer et al. 2012; Wink 1991). In the current paper, we focus exclusively on grandiose narcissism, which includes traits such as dominance, immodesty, callousness, and high levels of selfesteem (Weiss and Miller 2018). We examine the relationships between different aspects of narcissism and temperamental traits, referring to Gray's (1970) model considering the BIS (i.e., behavioural inhibition system) and the BAS

Łukasz Subramanian

lukassubramanian@gmail.com

Michał Sękowski

micsekowski@student.uksw.edu.pl

Magdalena Żemojtel-Piotrowska

m.zemojtel-piotrowska@uksw.edu.pl

1 Cardinal Stefan Wyszyński University in Warsaw, Dewajtis 5 Street, 01-815 Warsaw, Poland (i.e., behavioural activation system) as crucial motivational systems for behaviour and affect.

We focus on three manifestations of grandiose narcissism: agentic, antagonistic, and communal narcissism (Fatfouta et al. 2017). Defining the agentic and antagonistic aspects of narcissism we refer to the narcissistic admiration and rivalry framework (Back et al. 2013). Admiration reflects the assertive features of narcissism (Back et al. 2013; Rogoza et al. 2016), while rivalry reflects its malignant features (Back et al. 2013; Leckelt et al. 2015). Communal narcissism is framed within the agency-communion model of grandiose narcissism positing that the narcissists fulfil their core selfmotives through agentic or communal means (Gebauer et al. 2012). An agentic narcissist self-enhances on exceptional agency (e.g., intelligence or power), while a communal narcissist self-enhances on exceptional communion(e.g., tolerance or friendliness), therefore agentic and communal narcissism are two parallel forms of grandiose narcissism but they differ in the way in which the core narcissistic motives are fulfilled (Gebauer and Sedikides 2018). Antagonistic narcissism is separate from these both forms. That is, the core motivation of antagonistic narcissists is to defend their ego, while agentic and communal narcissists are motivated by boosting their ego (Fatfouta et al. 2017; Kwiatkowska et al. 2019). Admiration refers to a generally positive self-image, however, global self-esteem is built mostly on agentic traits (Wojciszke 
et al. 2011) and admiration correspond with that part of the Narcissistic Personality Inventory which refers to egoboosting part (Back et al. 2013). NPI-based narcissism is predominantly agentic (Grijalva and Zhang 2016). Therefore, we assume that admiration is also predominantly agentic.

BIS is based on septohippocampal system and its branches in the brainstem. This system is a mechanism controlling the experience of anxiety on stimuli that trigger this state. These incentives, being signals of punishment and lack of rewards, result in individuals refraining from achieving goals. BAS, based on dopaminergic conductivity, is sensitive to positive signals, rewards, and avoidance of penalties. BAS activation favours the regulation of purposeful behaviours and is combined with the emotions of hope and satisfaction (Gray 1970). There are (at least) three motivational aspects of BAS. Drive is understood as the persistent pursuit of desired goals, pleasure-seeking is defined as a desire for new rewards, and a willingness to approach a potentially rewarding event on the spur of the moment, and reward sensitivity is a focus on positive responses to the occurrence of anticipation of reward (Carver and White 1994).

Prior research indicated that the BAS was positively related to grandiose narcissism, while the BIS was related to grandiose narcissism negatively (Foster and Trimm IV 2008; Miles et al. 2019; Włodarska et al. 2019). However, in these studies, narcissism was treated as a homogeneous construct, mostly referring to its grandiose form (see Włodarska et al. 2019 for review). Therefore, the relationship between the BIS/BAS levels and the three aforementioned aspects of grandiose narcissism has still not been thoroughly examined. In particular, there is still little known about the temperamental basis of communal narcissism.

All aspects of BAS seem relevant to understanding the motivational underpinnings of grandiose narcissism, given that the latter is driven by agency (Gebauer and Sedikides 2018). Because this type of narcissism is associated with striving to achieving goals, BAS-drive will be associated with agentic, antagonistic, and communal narcissism. These goals could be different, as narcissistic motives could be achieved via agentic and communal aims (Gebauer et al. 2012); yet, they are still driven by higher agency (Gebauer and Sedikides 2018). Therefore, there is an unresolved problem concerning to what extent the communal and agentic narcissism are parallel regarding to their temperamental basis. An open question also remains in regard to how antagonistic narcissism differs from communal and agentic narcissism, as it is related to self-protection, while agentic (and probably communal, see Gebauer et al. 2012) narcissism is related to self-promotion (Back et al. 2013; Back 2018).

Based on the aspects of the BAS (i.e. drive, pleasure-seeking, and sensitivity to reward), we predict that this system is positively correlated with all of the aspects of grandiose narcissism (see also Włodarska et al. 2019); however, the strength of these associations could be different for different aspects of narcissism. Agentic narcissism should be related most strongly to the BAS (all aspects) because striving to achieve goals and self-enhancement in the agentic domain (Gebauer et al. 2012; Grijalva and Zhang 2016). Communal narcissism should also be positively associated with BAS (all aspects), but less so than agentic, because the communal narcissists self-enhance in the communal domain (Gebauer and Sedikides 2018), so that achieving goals is related rather to self-presentation (e.g., being nice or friendly) than undertaking an action per se. Prior studies also indicated that antagonistic narcissism was positively related to BAS (MacLaren and Best 2013). Because antagonistic narcissism is related to competition and to the pursuit of dominance over others (Back et al. 2013), we expect its positive relationship with BAS.

The drive aspect of the BAS is related to undertaking action and persistence in continuing behaviours until satisfaction is achieved, so it should be related to all aspects of grandiose narcissism. We expect that only agentic and communal narcissists indicate higher levels of pleasure seeking, because pleasure-seeking is related to the search for positive stimuli. Antagonistic narcissism is reactive rather than active (Back 2018; Back et al. 2013; McDonald and Verona 2019), therefore we expect no relationship with this aspect of BAS. Given that sensitivity to rewards is a tendency towards excitement in response to the cues of potential reward or relief of punishment, therefore, again, this aspect of BAS should be positively related to agentic and communal narcissism but unrelated to antagonistic narcissism, as it is motivated mainly by selfprotection activities (Back 2018).

On the other hand, the BIS should correlate negatively with grandiose narcissism because it is related to punishment orientation (Gray 1970). In relation to BIS, we do not predict differences in the strength of the relationship with agentic and communal narcissism, yet we expect a stronger relationship with antagonistic narcissism as it is related to egoprotection (Back et al. 2013).

Narcissism is grounded in temperamental traits, including BIS/BAS (Foster and Trimm IV 2008), yet relations between agentic, communal, and antagonistic narcissism to approaching and avoiding motivation are still understudied. Give that different aspects of narcissism (e.g., agentic, antagonistic, and communal) are related to different outcomes (Fatfouta et al. 2017; Kwiatkowska et al. 2019), examining their relationship to temperamental traits would shed new light on their motivational basis.

\section{Method}

\section{Participants and Procedure}

We administered a two-wave survey to a representative (regarding sex, age, and education level) sample of 1100 Polish 
adults via the Ariadna research panel, as a part of broader project on narcissism (the other unreported data were not analysed here, and the current data were not analysed elsewhere). The two waves were separated by a week. In the first wave, narcissism was assessed and in the second temperamental traits were measured. The order of scales was randomized for each participant. Our final sample comprised 657 participants (372 women, $285 \mathrm{men} ; M_{\mathrm{age}}=45.04$ years, $\left.S D=15.44\right)$ aged 18 to 82; after excluding respondents who (a) did not take part in the second wave $(n=288)$ or (b) failed to answer correctly an at least one of three (for each wave) attention check items (e.g., "Please select response option 5") $(n=155)$. All participants were Polish residents, and all measures were administered in Polish. All procedures were approved by the institutional ethics board (KEiB - 10/2018). Data are available at osf.io/m5ybq.

\section{Measures}

Agentic and Antagonistic Narcissism The Narcissistic Admiration and Rivalry Questionnaire (NARQ; Back et al. 2013) is an eighteen-item measure of narcissism distinguishing its agentic and antagonistic facets as narcissistic admiration (9 items; e.g., I deserve to be seen as a great personality) and narcissistic rivalry ( 9 items each; e.g., I react annoyed if another person steals the show from me), respectively. Respondents answered using a six-point Likert-type scale ranging from 1 (not agree at all) to 6 (agree completely).

Communal narcissism was measured by the 16-item Communal Narcissism Inventory (CNI; Gebauer et al. 2012), derived from A-C model of narcissism (e.g., I will be well known for the good deeds I will have done). Respondents answered using a seven-point Likert-type scale ranging from 1 (disagree strongly) to 7 (agree strongly).

Approach-Avoidance Motivation The BIS/BAS scale is a 24item behavioural inhibition system (BIS) and behavioural activation system (BAS), which is a purpose-driven measure of avoidance and approach (motivation, respectively (Carver and White 1994). Thirteen items reflect approach (e.g., I go out of my way to get things I want) and are divided into three aspects: drive (e.g., I will do everything, despite the obstacles, to get what I want), pleasure-seeking (e.g., I often do things just for fun), and sensitivity to reward (e.g., Winning the competition would be exciting). Seven items reflect avoidance (e.g., Criticism or scolding hurts me quite a bit). There were also four filler items (e.g., A person's family is the most important thing in life). Respondents answered using a four-point Likert-type scale ranging from 1 (very false) to 4 (very true).

\section{Results}

Zero-order correlations, descriptive statistics, and reliability estimates (Cronbach's alphas) for all studied variables are presented in Table 1.

The three aspects of BAS were positively correlated to each other. All aspects of narcissism correlated positively with drive, pleasure-seeking, and sensitivity to reward. Agentic narcissism negatively correlated with BIS, antagonistic narcissism positively correlated with BIS, while communal narcissism was unrelated to BIS.

To compare the strength of the correlations, $z$-tests for dependent samples were performed using an online calculator (Eid et al. 2011). Results are presented in Table 2.

The relationship between agentic narcissism and BAS-drive was stronger than analogous relationships for communal and antagonistic narcissism. Communal and antagonistic narcissism were related to BAS-drive with the same strength. Agentic narcissism was most strongly related to BAS-pleasure-seeking, followed by communal narcissism and antagonistic narcissism. The relationship between agentic narcissism and sensitivity to reward was stronger than analogous relationships of communal and antagonistic narcissism. There was no difference in the strength of the relationship with BAS-sensitivity to reward for communal and antagonistic narcissism.

There were no differences in the strength of relations with BIS for agentic and communal narcissism. Antagonistic narcissism was related more strongly to BIS than agentic and communal narcissism.

In aim to examine the unique relationships between temperamental traits and narcissism we conducted three regressions. In all regressions, agentic, communal, and antagonistic narcissism were outcome variables. In the first step we controlled sex and age as they are typically related to temperament (Pagliaccio et al. 2016) and narcissism (Grijalva et al. 2015). In the second step we entered the three aspects of BAS and the BIS measure as predictors. In the third step we included interactions between sex and temperamental traits in aim to check whether the patterns of relations between temperament and narcissism are similar across sexes. Results are presented in Table 3.

In the first step of regressions, we found that higher levels of agentic and communal narcissism were higher among women, while antagonistic narcissism was higher among men. All aspects of narcissism were predicted negatively by age (see Table 3 for details). Interaction terms explained an additional $2 \%$ variance for agentic narcissism $(\Delta F[4,646]=$ $3.07, p=.016$ ). There were no significant interactions in the remaining models (in communal and antagonistic, $\Delta F$ not significant). The only interaction was between sex and BAS pleasure seeking where the relationship was present in men $(\beta=.25,95 \%$ CI $[.12, .38] p<.001)$ but not in women $(\beta=.02,95 \%$ CI $[-.09, .12] p=.762)$. 
Table 1 Means, Standard Deviations, Internal Consistency Estimates, and Zero-Order Correlation Coefficients of Studied Variables

\begin{tabular}{|c|c|c|c|c|c|c|c|}
\hline & 1 & 2 & 3 & 4 & 5 & 6 & 7 \\
\hline \multicolumn{8}{|l|}{ 1. Agentic narcissism } \\
\hline 2. Communal narcissism & $.55 * * *$ & & & & & & \\
\hline 3. Antagonistic narcissism & $.38 * * *$ & $.09 *$ & & & & & \\
\hline 4. BIS & $-.09 *$ & -.07 & $.11 * *$ & & & & \\
\hline 5. BAS drive & $.40 * * *$ & $.26 * * *$ & $.22 * * *$ & $-.12 * *$ & & & \\
\hline 6. BAS pleasure-seeking & $.34 * * *$ & $.24 * * *$ & $.12 * *$ & -.07 & $.49 * * *$ & & \\
\hline 7. BAS sensitivity to reward & $.35 * * *$ & $.18 * * *$ & $.10^{* *}$ & $.22 * * *$ & $.47 * * *$ & $.47 * * *$ & \\
\hline$M$ & 3.11 & 3.41 & 2.31 & 2.74 & 2.49 & 2.53 & 3.03 \\
\hline$S D$ & .93 & .80 & .97 & .52 & .61 & .57 & .47 \\
\hline Cronbach's $\alpha$ & .87 & .92 & .89 & .76 & .74 & .66 & .70 \\
\hline
\end{tabular}

$N=657 . B I S$ the behavioural inhibition system, $B A S$ the behavioural activation system

$p<.05^{*} ; p<.01 * * ; p<.001 * * *$
In the final model, agentic narcissism was positively related to all aspects of the BAS and negatively with the $\operatorname{BIS}(F[10$, $646]=19.86, p<.001$ ) with $24 \%$ of the variance in agentic narcissism explained. Communal narcissism was positively related to drive and pleasure-seeking, was unrelated to sensitivity to reward, and negatively related with the BIS ( $F[10$, $646]=8.19, p<.001)$ with $11 \%$ of the variance in agentic narcissism explained. Antagonistic narcissism was positively related to drive, was unrelated to pleasure-seeking and sensitivity to reward, and was positively related to the BIS ( $F[10$, $646]=8.55, p<.001)$ with $12 \%$ of the variance in antagonistic narcissism explained.

\section{Discussion}

The aim of the current study was to examine the relationship between the three forms of narcissism (i.e., agentic, communal and antagonistic) and temperament, expressed via BIS/BAS. We focused on both the direction and the strength of these relationships. We expected the three different forms of narcissism to be positively related to the three aspects of the behavioural activation system (BAS): drive, pleasure-seeking, and sensitivity to reward. We also assumed that various types of narcissism would be negatively associated with the behavioural inhibition system (BIS).

Our results show that agentic narcissism is correlated positively with all three BAS aspects (drive, pleasure-seeking, and sensitivity to reward), congruent with the proactive nature of agentic narcissism (Back et al. 2013; Grijalva and Zhang 2016), however positive relation between pleasure seeking and agentic narcissism was found only among men. Communal narcissism is related positively with drive and pleasure-seeking, and is unrelated to sensitivity to reward. Despite communal narcissism being based on grandiose narcissistic motives, they are realized not by agency but by communion (Gebauer and Sedikides 2018). As a result, communal narcissism is related only to drive (because of a focus on achieving goals) and to pleasure-seeking (because of a focus on positive events), but sensitivity to reward could be related more to an agentic than a communal domain. However, this explanation does require further studies. Antagonistic narcissism related only with the drive aspect of BAS. It is the most reactive form among all narcissism forms studied here (Gebauer et al. 2012), and thus we suppose that it could be just goal-oriented and not related to looking for reward itself. Antagonistic narcissism is a defence of threated ego, the emergency system which is activated when an individual is
Table 2 Comparison of correlations from independent samples (z-tests for dependent samples)

\begin{tabular}{lccc}
\hline & $\begin{array}{l}\text { Agentic vs communal } \\
\text { narcissism }\end{array}$ & $\begin{array}{l}\text { Agentic vs } \\
\text { antagonistic narcissism }\end{array}$ & $\begin{array}{l}\text { Communal vs } \\
\text { antagonistic narcissism }\end{array}$ \\
\hline BIS & -0.62 & $-4.61^{* * *}$ & $-4.08^{* * *}$ \\
BAS drive & $4.05^{* * *}$ & $4.46^{* * *}$ & 0.81 \\
BAS pleasure-seeking & $4.39^{* * *}$ & $5.26^{* * *}$ & $2.29^{*}$ \\
BAS sensitivity to reward & $4.86^{* * *}$ & $6.06^{* * *}$ & 1.56 \\
\hline
\end{tabular}

$N=657 . B I S$ the behavioural inhibition system, $B A S$ the behavioural activation system. Comparison of correlations from dependent samples (two-tailed)

$p<.05^{*} ; p<.01 * * ; p<.001 * * *$ 


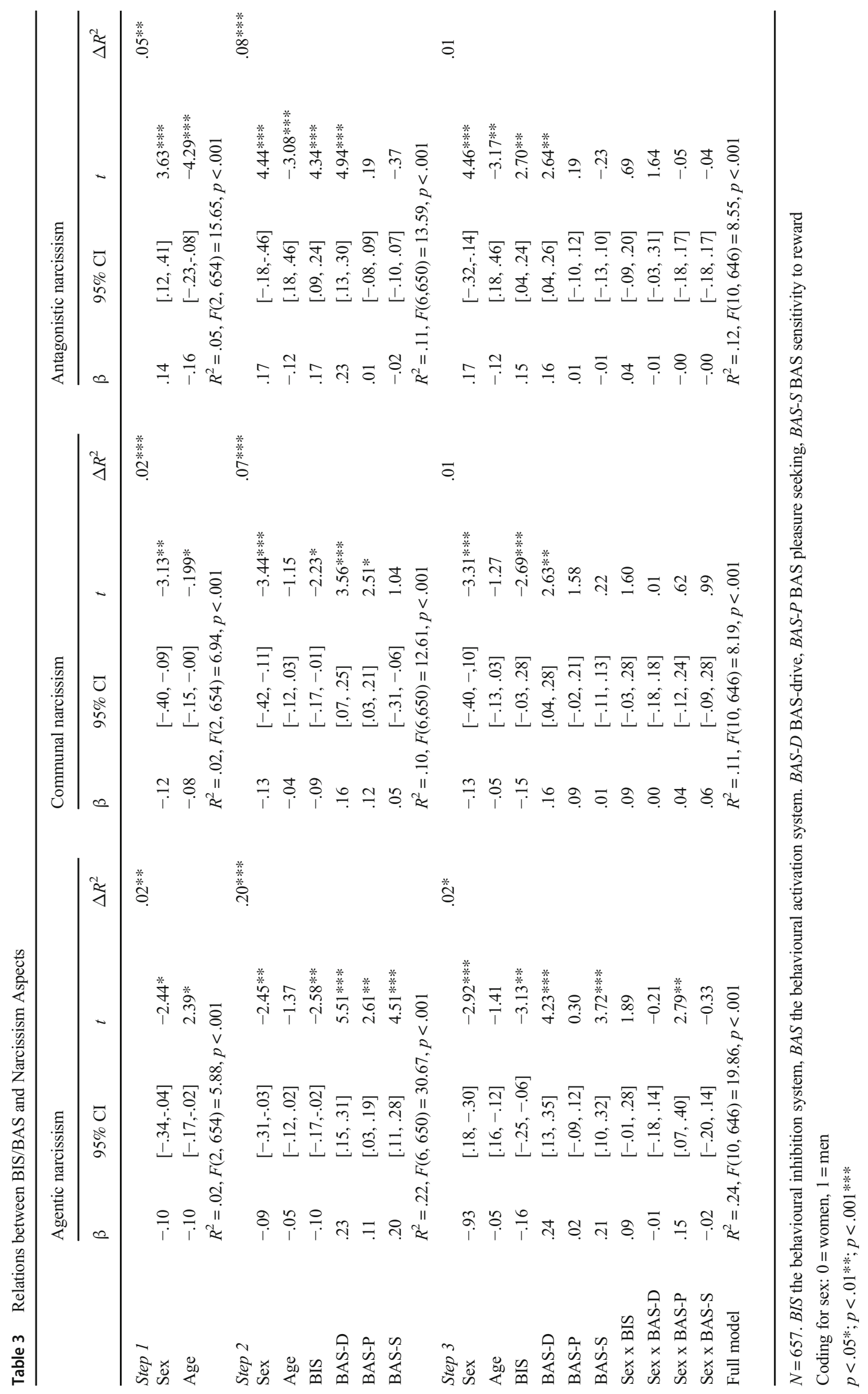


threatened by an aversive situation (Back et al. 2013). Therefore, the main motivation related to antagonistic narcissism is to avoid unpleasant events.

BIS is related negatively with agentic and communal narcissism, which can mean that agentic and communal narcissists do not inhibit their actions (Gebauer and Sedikides 2018). Therefore, agentic and communal narcissists are the ones who are not preoccupied by the possibility of failure (Gebauer and Sedikides 2018). On the other hand, antagonistic narcissism is related positively to BIS. Antagonistic narcissism is more reactive than active, and is related positively to anxiety (Back 2018). As BIS is correlated with negative emotions such as anxiety and frustration (Gray 1970), antagonistic narcissism, preoccupied with detecting threats to the ego, is motivationally based on BIS rather than BAS.

Agentic and communal narcissism turned out to be different in their relations to BIS and BAS, so that they are not fully analogous in relation to their temperamental basis (Luo et al. 2016). Agentic narcissism was related more strongly to BAS than its communal counterpart, which is congruent with the agency-communion model of grandiose narcissism (Gebauer and Sedikides 2018). However, they are both unrelated to BIS, congruent with their grandiose nature (Włodarska et al. 2019). Antagonistic narcissism was different from both agentic and communal narcissism. It was related more weakly to BAS than agentic and communal narcissism, and more strongly to BIS than these two facets. Therefore, the temperamental basis of antagonistic narcissism is distinct from agentic and communal narcissism, congruent with its reactive nature (Back 2018). In general, all relations between narcissism and BIS/BAS were rather weak to moderate, with the highest percent of explained variance being for agentic narcissism. Therefore, narcissism, at least the aspects studied in the current research, are rather BAS-based, related to achieving goals, than BIS-based, related to ego-protection, congruent with the grandiose nature of agentic, communal and, to some extent, antagonistic narcissism.

\section{Limitations and Future Directions}

The current study is a self-report cross-sectional one; therefore, it is not clear to what extent the results obtained are biased due to narcissistic self-enhancement, especially as related to narcissistic self-presentation being proactive and agentic (Grijalva and Zhang 2016). On the other hand, there is a lot of evidence for the usefulness of BIS/BAS in the studies on narcissism (see Włodarska et al. 2019 for review). Further studies should supplement the current findings concerning the biological indicators of temperament and related to performance tasks. For instance, antagonistic narcissism seems to be motivationally distinct from agentic and communal narcissism so that its status as an aspect of grandiose or vulnerable narcissism is worth further examination, as is its relation to temperamental traits.

\section{Conclusions}

Overall, the current study provides evidence to distinguish three facets of grandiose narcissism (agentic, communal, and antagonistic), suggesting a distinctiveness of the antagonistic aspect from the agentic and communal. All three forms were positively related to BAS, while only antagonistic narcissism was positively related to BIS. Our findings are congruent with the newest concepts of narcissism, placing the antagonistic aspect between grandiose and vulnerable narcissism (Krizan and Herlache 2018; Weiss et al. 2019). As the current research was based on self-report cross-sectional data, further research would benefit from using physiological indicators associated with BIS/BAS.

Funding Information This study was funded by Polish National Science Centre (grant number 2017/26/E/HS6/00282).

\section{Compliance with Ethical Standards}

Conflict of Interest The authors declare that they have no conflict of interest.

All procedures were approved by the institutional ethics board (KEiB -10/2018). Informed consent was obtained prior to data collection from each participant. Data will be available as a part of the submission via osf link.

Open Access This article is licensed under a Creative Commons Attribution 4.0 International License, which permits use, sharing, adaptation, distribution and reproduction in any medium or format, as long as you give appropriate credit to the original author(s) and the source, provide a link to the Creative Commons licence, and indicate if changes were made. The images or other third party material in this article are included in the article's Creative Commons licence, unless indicated otherwise in a credit line to the material. If material is not included in the article's Creative Commons licence and your intended use is not permitted by statutory regulation or exceeds the permitted use, you will need to obtain permission directly from the copyright holder. To view a copy of this licence, visit http://creativecommons.org/licenses/by/4.0/.

\section{References}

Back, M. D. (2018). The narcissistic admiration and rivalry concept. In A. D. Hermann, A. Brunell, \& J. Foster (Eds.), The handbook of trait narcissism (pp. 57-67). Cham: Springer International Publishing.

Back, M. D., Küfner, A. C. P., Dufner, M., Gerlach, T. M., Rauthmann, J. F., \& Denissen, J. J. A. (2013). Narcissistic admiration and rivalry: Disentangling the bright and dark sides of narcissism. Journal of Personality and Social Psychology, 105, 1013-1037. https://doi. org/10.1037/a0034431.

Carver, C. S., \& White, T. L. (1994). Behavioral inhibition, behavioral activation, and affective responses to impending reward and punishment: The BIS/BAS scales. Journal of Personality and Social 
Psychology, 67, 319-333. https://doi.org/10.1037/0022-3514.67.2. 319.

Eid, M., Gollwitzer, M., \& Schmitt, M. (2011). Statistik und forschungmethoden lehrbuch [textbook of statistics and research methods]. Weinheim: Beltz.

Fatfouta, R., Zeigler-Hill, V., \& Schröder-Abé, M. (2017). I'm merciful, am I not? Facets of narcissism and forgiveness revisited. Journal of Research in Personality, 70, 166-173. https://doi.org/10.1016/j.jrp. 2017.07.007.

Foster, J. D., \& Trimm IV, R. F. (2008). On being eager and uninhibited: Narcissism and approach-avoidance motivation. Personality and Social Psychology Bulletin, 34, 1004-1017. https://doi.org/10. 1177/0146167208316688.

Gebauer, J. E., \& Sedikides, C. (2018). Agency and communion in grandiose narcissism. In A. E. Abele \& B. Wojciszke (Eds.), Agency and communion in social psychology (pp. 90-102). Routledge.

Gebauer, J. E., Sedikides, C., Verplanken, B., \& Maio, G. R. (2012). Communal narcissism. Journal of Personality and Social Psychology, 103, 854-878. https://doi.org/10.1037/a0029629.

Gray, J. A. (1970). The psychophysiological basis of introversion-extraversion. Behaviour Research and Therapy, 8, 249-266. https://doi. org/10.1016/0005-7967(70)90069.

Grijalva, E., \& Zhang, L. (2016). Narcissism and self-insight: A review and meta-analysis of narcissists' self-enhancement tendencies. Personality and Social Psychology Bulletin, 42, 3-24.

Grijalva, E., Newman, D. A., Tay, L., Donnellan, M. B., Harms, P. D., Robins, R. W., \& Yan, T. (2015). Gender differences in narcissism: A meta-analytic review. Psychological Bulletin, 141(2), 261. https:// doi.org/10.1037/a0038231

Kwiatkowska, M., Jułkowski, T., Rogoza, R., Żemojtel-Piotrowska, M., \& Fatfouta, R. (2019). Narcissism and trust: Differential impact of agentic, antagonistic and communal narcissism. Personality and Individual Differences, 137, 139-143. https://doi.org/10.1016/j. paid.2018.08.027.

Krizan, Z., \& Herlache, A. D. (2018). The narcissism spectrum model: A synthetic view of narcissistic personality. Personality and Social Psychology Review, 22, 3-31. https://doi.org/10.1177/ 1088868316685018.

Leckelt, M., Küfner, A. C. P., Nestler, S., \& Back, M. D. (2015). Behavioral processes underlying the decline in narcissists' popularity over time. Journal of Personality and Social Psychology, 109, 856-871. https://doi.org/10.1037/pspp0000057.

Luo, Y. L. L., Liu, Y., Cai, H., Wildschut, T., \& Sedikides, C. (2016). Nostalgia and self-enhancement: Phenotypic and genetic approaches. Social Psychological and Personality Science, 7, 857866. https://doi.org/10.1177/1948550616660158.

MacLaren, V. V., \& Best, L. A. (2013). Disagreeable narcissism mediates an effect of BAS on addictive behaviors. Personality and Individual Differences, 55, 101-105. https://doi.org/10.1016/j.paid.2013.02. 004 .

McDonald, J., \& Verona, E. (2019). Biological correlates of antagonism. In J. D. Miller \& D. R. Lynam (Eds.), The handbook of antagonism.
Conceptualizations, assessment, consequences, and treatment of the low end of agreeableness (pp. 81-96). San Diego, CA, US: Elsevier Academic Press. https://doi.org/10.1016/B978-0-12-814627-9. 00006-2.

Miles, G. J., Smyrnios, K. X., Jackson, M., \& Francis, A. (2019). Reward-punishment sensitivity bias predicts narcissism subtypes: Implications for the etiology of narcissistic personalities. Personality and Individual Differences, 141, 143-151. https://doi. org/10.1016/j.paid.2019.01.004.

Miller, J. D., Lynam, D. R., Hyatt, C. S., \& Campbell, W. K. (2017). Controversies in narcissism. Annual Review of Clinical Psychology, 13, 291-315. https://doi.org/10.1146/annurev-clinpsy-032816045244.

Pagliaccio, D., Luking, K. R., Anokhin, A. P., Gotlib, I. H., Hayden, E. P., Olino, T. M., Peng, C. Z., Hajcak, G., \& Barch, D. M. (2016). Revising the BIS/BAS scale to study development: Measurement invariance and normative effects of age and sex from childhood through adulthood. Psychological Assessment, 28, 429-442. https://doi.org/10.1037/pas0000186.

Rogoza, R., Żemojtel-Piotrowska, M., Rogoza, M., Piotrowski, J., \& Wyszyńska, P. (2016). Narcissistic admiration and rivalry in the context of personality metatraits. Personality and Individual Differences, 102, 180-185. https://doi.org/10.1016/j.paid.2016.07. 003.

Weiss, B., Campbell, W. K., Lynam, D. R., \& Miller, J. D. (2019). A trifurcated model of narcissism: On the pivotal role of trait antagonism. In J. Miller \& D. Lynam (Eds.), The handbook of antagonism. Conceptualizations, assessment, consequences, and treatment of the low end of agreeableness (pp. 221-235). San Diego, CA, US: Elsevier Academic Press. https://doi.org/10.1016/B978-0-12814627-9.00006-2.

Weiss, B., \& Miller, J. D. (2018). Distinguishing between grandiose narcissism, vulnerable narcissism, and narcissistic personality disorder. In A. D. Hermann, A. B. Brunell, \& J. D. Foster (Eds.), Handbook of trait narcissism (pp. 3-13). Cham: Springer International Publishing.

Włodarska, K. A., Zyskowska, E., Terebus, M. K., \& Rogoza, R. (2019). The dark triad and BIS/BAS: A meta-analysis. Current Psychology, 1-9, online first. https://doi.org/10.1007/s12144-019-00467-8.

Wink, P. (1991). Two faces of narcissism. Personality and Individual Differences, 61, 590-597. https://doi.org/10.1037/0022-3514.61.4. 590.

Wojciszke, B., Baryla, W., Parzuchowski, M., Szymkow, A., \& Abele, A. E. (2011). Self esteem is dominated by agentic over communal information. European Journal of Social Psychology, 41(5), 617627.

Publisher's Note Springer Nature remains neutral with regard to jurisdictional claims in published maps and institutional affiliations. 